\title{
ESTRATEGIAS METODOLÓGICAS UTILIZADAS POR DOCENTES DE SÉTIMO AÑO EN LA ENSEÑANZA DEL ANÁLISIS DE TEXTOS LITERARIOS
}

\author{
Catalina Ramírez Molina \\ El problema: Los estudiantes tienen \\ profesores con formación del siglo XX \\ en pleno siglo XXI \\ Martín- Barbero
}

\begin{abstract}
RESUMEN
Los problemas de acercamiento de los estudiantes hacia la lectura han sido un tema relevante pero carente de un análisis exhaustivo o riguroso -por parte de las autoridades del Ministerio de Educación Pública y docentes-; que permita ubicar la problemática, describirla, analizarla y reflexionar en torno a propuestas concretas y útiles al servicio del docente y, principalmente, del estudiante.

Por lo tanto, la investigación que se realizó muestra un acercamiento a la condición actual del estudiante y el docente de secundaria frente al proceso de enseñanza-aprendizaje del análisis de textos literarios; su participación, vinculación o limitación en el campo de la literatura; así como los efectos y los alcances de una escuela que está cambiando y su transformación se centra en las experiencias, necesidades, sensibilidades, cultura, proyectos y nuevos espacios de socialización de los estudiantes. Palabras clave: estudiantes, docentes, proceso de enseñanza-aprendizaje, análisis de textos literarios, literatura.
\end{abstract}

\begin{abstract}
There has been a major concern in Costa Rica regarding how to approach students with the task of reading. However neither the MEP authorities nor the teachers have carried out the rigorous research needed.

Such research will provide the basis for identifying, describing, analyzing these issues concerning students and teachers in order to develop proposals.

Therefore, this investigation opens a window into the real world of how teachers and students face the roll of teaching and learning text analysis respectively and also many aspects involved in this process, like people participation, contributions and limitations, some of these, intrinsic to the system.

One of the most important things to understand about the subject, is that the motor of the ever changing dynamics of the school is moved by the students experiences, needs, sensibilities, culture, projects and new socialization spaces.

Key words: students, teachers, teaching- learning process, text analysis, literature.
\end{abstract}

Catalina Ramírez Molina. Licenciada en la Enseñanza del Castellano y Literatura, profesora de español en el Liceo de Heredia.

Correo electrónico: katalitika@hotmail.com

Recepción: 22- 10- 2007

Aceptación: 27- 11- 2007 


\section{Justificación}

\subsection{Muchas interrogantes, pocas soluciones}

Los docentes que aún tenemos el privilegio de estar en contacto con estudiantes de secundaria, nos preguntamos por qué en este tiempo, en donde la saturación de imágenes, información y demás, es tan fuerte, a ellos aún no se les permite o incentiva a defenderse: discriminar o bien formular un criterio personal ante lo que ven y escuchan diariamente.

¿Cómo transmitirles que un libro es y existe porque alguien lo lee libremente, lo acaricia, lo enoja, lo desilusiona o hasta lo enamora?, ¿cómo contagiar la idea de que un libro sin lector no es nada?, ¿cómo incitar un encuentro placentero con el libro y volver al sitio en donde nos enojamos, compartimos, imaginamos y enamoramos?

Estas interrogantes impulsaron la investigación titulada Estrategias metodológicas utilizadas por docentes de sétimo año en la enseñanza del análisis de textos literarios (Ramírez 2007). Y de esta investigación nace este artículo que me dispongo a compartir.

A través de la búsqueda realizada para hallar estudios relacionados con las estrategias utilizadas por los docentes en la enseñanza de análisis de textos literarios, se encontraron múltiples estudios (Lomas 2003, Martín-Barbero 2002, López 2005, Ostria 2003, Quiroz 2003, Sánchez 2003) sobre la crisis que enfrenta el Sistema Educativo, en el área de enseñanza de la literatura y, específicamente, en el proceso de lectura que realizan los estudiantes, actualmente, en los salones de clase.

Estos trabajos ponen en evidencia diversas interrogantes y posibles causas por la falta de motivación hacia la lectura de parte de los alumnos del Tercer Ciclo de la Enseñanza General Básica.

Algunas de las preguntas que se hallaron en esta revisión fueron: ¿Cómo enseñan los docentes de español los textos literarios?, ¿cuáles son las habilidades de lectura de los estudiantes?, ¿cuáles y cómo son los textos literarios que deben leer en primaria y en secundaria? ¿Son significativos para ellos y logran un verdadero análisis literario?, ¿qué impacto causan los medios de comunicación masiva en la actitud de los estudiantes hacia la literatura?, ¿qué tipo de textos les gusta leer?, ¿es posible diseñar técnicas apropiadas y eficaces para mejorar la mediación docente en la enseñanza de textos literarios, y, al mismo tiempo, lograr que los estudiantes se acerquen a la literatura?, ¿qué y cómo se puede enseñar-aprender-evaluarcalificar en la materia de literatura? Éstas y otras preguntas se centran en una problemática que apunta a la necesidad de analizar y evaluar detalladamente los elementos que intervienen en el proceso de la enseñanza de la literatura y demostrar qué factores obstaculizan dicho proceso. Sin embargo, a pesar de los estudios realizados, aún no se enfatiza cómo se comportan los actores (estudiantes, docentes, programas de Español del Ministerio de Educación Pública) en el proceso y cuáles limitaciones encuentran o qué elementos socioculturales los afectan.

Para responder a estas preguntas, se realizaron seis observaciones de aula y se entrevistó a diez estudiantes y dos docentes de español.

Pero antes de entrar en el análisis de los resultados, es importante detenerse en un elemento muy discutido pero poco comprendido aún: la brecha generacional. 


\subsection{El elemento olvidado: la brecha generacional}

El fenómeno de rechazo a los libros, por parte de los estudiantes, en los centros educativos, es explicado por el antropólogo Jesús Martín-Barbero en su artículo "Jóvenes: comunicación e identidad" (2002). En él se plantea que existen cambios que experimentan los adolescentes y jóvenes de hoy, pero quienes más experimentan el cambio son los adultos. Es decir, éstos se ven ante una generación regida por la tecnología, lo que provoca una incomunicación entre los adultos y los jóvenes.

Por su parte, María Rosa Solano (2000) en su artículo "El proceso de enseñanzaaprendizaje de la lectura" considera que la sociedad actual lanza retos novedosos que producen en los adolescentes disfrute inmediato y resultan más atractivos. Este factor causa la desmotivación del estudiante por la lectura, ya que ésta no ha sido fuente de vivencias importantes para él. A este factor se suma, de acuerdo con Solano, la forma en que los docentes enseñan la lectura: de un modo mecánico y superficial, que no consigue explotar el material leído a través de la criticidad, el ingenio, ni la creatividad. Para los estudiantes, los docentes han convertido la lectura en una experiencia árida y estéril, la cual no enriquece su visión de mundo.

Retomando el fenómeno que expone Martín-Barbero, sobre las nuevas tecnologías, se establece una ruptura de diálogo entre las nuevas y viejas generaciones, lo que provoca una incomunicación entre la nueva manera como los adolescentes perciben el mundo y la antigua forma de los adultos de acceder a los conocimientos. J. Meyrowitz, citado por MartínBarbero, señala que:

\footnotetext{
Desde el siglo XVII hasta mediados del siglo XX, el mundo de los adultos había creado unos espacios propios de saber y de comunicación de los cuales mantenía apartados a los niños (...) Desde mediados de nuestro siglo, esa separación de mundos se ha disuelto, por la acción de la televisión que, al transformar los modos de circulación de la información en el hogar, rompe el vínculo paternal (...) Lo revolucionario en la televisión es que ella permite a los más jóvenes estar presentes en las interacciones de los adultos (2002: 2).
}

Esta explicación concuerda con Heinz Shulte- Herbrüggen en su artículo "El lenguaje un medio para apoderarse mentalmente del mundo" (1997: 37), al señalar que el hecho de que un niño nazca en una definida comunidad histórica tiene consecuencias trascendentales para su manera de comprender el mundo. Es decir, que las nuevas generaciones perciben el mundo de otra manera y, como consecuencia, están aprendiendo a leer de otra manera también. Sus interacciones poseen nuevas sensibilidades; como bien lo señala Martín-Barbero (2002: 4), “(...) ven el mundo a través de imágenes, sonoridades, fragmentaciones y velocidades en las cuales encuentran su idioma y su ritmo".

Ante este panorama, según Martín-Barbero, los jóvenes habitan un nuevo espacio comunicacional frente a los letrados; de aquí la incongruencia entre generaciones. "Mientras el maestro recita su lección, el alumno se halla "empapado" de otros lenguajes, saberes y escrituras que circulan por la sociedad" (2002: 6).

En este sentido, Quiroz, en su libro Aprendizaje y comunicación en el siglo XXI, afirma que:

La lectura de un libro requiere la decisión de abrirlo y cerrarlo. La televisión en cambio, ubicada en la casa, permite que los mundos imaginarios fluyan y se mezclen con los de la vida diaria, creando las condiciones de una transición más fluida y continua entre lo real y lo imaginario (2003: 34). 
Desde esta perspectiva, el estudiante discrimina entre aquello que le produce atracción y aquello que le produce sensación de deber.

Por tal motivo, Ostria (2005: 8), en su artículo "La enseñanza de la literatura en los tiempos que corren", cita a Martín-Barbero y señala que el proceso de leer, en la actualidad, implica profundos cambios, entendiendo que la lectura no solamente es un modo de relación con el libro, sino con la pluralidad y heterogeneidad de textos y escrituras que hoy circulan.

De esta manera, Quiroz (2003) cita a Constantino Carballo y señala:

(...) A la lentitud del diálogo interior se ha impuesto la velocidad de la presencia virtual de los datos y de nadie en un concierto de solitarios acompañados por la bulla y las imágenes(...) Pienso que los jóvenes no saben aburrirse y que la velocidad es una exigencia que se traslada luego al mundo real, que deviene en decepción y molestia. Es difícil atender y escuchar el discurso del maestro porque es lento y no cambia como debiera de un lado a otro. Es imposible tolerar la literatura con su inmovilidad y su demanda de atención sobre lo mismo (2003: 84-85).

Como vemos, las razones expuestas anteriormente ponen en evidencia la necesidad de estudiar, a profundidad, la manera en que se está enseñando el análisis de textos literarios en el salón de clase, con el propósito de lograr repuestas que valoren la labor docente y que los estudiantes sean beneficiarios directos, al retomar la importancia de heredar el gusto por la literatura, la cual le permitirá desarrollar su creatividad, la creación de un pensamiento abstracto, el logro de una formación integral que le enseñe a leer su entorno y a integrar los aspectos de su vida.

\section{El diagnóstico}

\subsection{Tipo de investigación}

El estudio que se llevó a cabo se centró en el marco de una investigación exploratoriadescriptiva-cualitativa.

Esta investigación se realizó con el propósito de conocer las estrategias metodológicas que utilizan los docentes de sétimo año en la enseñanza del análisis de textos literarios. El estudio constó de seis observaciones de aula, entrevistas a docentes y estudiantes.

Las observaciones de aula se realizaron en una institución educativa pública: Liceo de Heredia y se trabajó con el $100 \%$ de la población de docentes que impartían, únicamente, el nivel de sétimo año, el cual correspondía a dos profesoras.

Esta población posee categoría MT4 y tienen, aproximadamente, diecisiete años de trabajar en la materia de Español. Son consideradas por el director de la institución como excelentes, debido a su trabajo y a la buena promoción tanto en noveno como en undécimo año.

Los sujetos observados son estudiantes de sétimo año y poseen una edad aproximada entre los 12 y los 14 años. Para efectos del estudio se entrevistó en dos ocasiones a diez estudiantes. Como se observaron dos docentes, se entrevistó a cinco alumnos por cada una de ellas. La primera entrevista a los estudiantes se realizó a principios del 2006, y la segunda durante el último trimestre lectivo de este año.

Ambas entrevistas se realizaron con el propósito de verificar si las apreciaciones sobre el análisis de textos literarios, de los estudiantes entrevistados, cambiaban a través del desarrollo del proceso de enseñanza-aprendizaje durante un mismo año lectivo. 


\subsection{Vida en el aula}

En las observaciones de aula se encontraron varios elementos que intervienen en el proceso de enseñanza-aprendizaje de la literatura. Me interesa, para este artículo, exponer ampliamente la manera en que se comportan e interactúan los actores, en este caso, los estudiantes, docentes y programas de estudio del Español, dentro del aula.

Los elementos que me dispongo a analizar son:

a) Relación entre estudiantes y profesora.

b) Enseñanza de la literatura.

c) Tareas para abordar el análisis literario.

d) Tipo de lectura que realizan los estudiantes.

En el primer elemento, se encontró que el concepto de espacio-clase se ve marcado por el tradicionalismo (profesor-enseña, estudiante-aprende), lo que provoca un distanciamiento que trae como consecuencia una apatía y pasividad por parte del estudiantado, que entorpece el desarrollo activo de lo que se pretende enseñar.

Durante las seis observaciones, los estudiantes se ubicaron en hileras y la docente en su escritorio. Ésta permaneció allí todas las lecciones. Este aspecto manifiesta que durante el desarrollo de las clases no existió un acercamiento al estudiante por parte de la profesora. Esta condición muestra la delimitación de espacios aún existente en el salón de clase. Los estudiantes se sientan en sus respectivos pupitres y las profesoras explican toda la materia, desde su escritorio.

Este factor demuestra la poca comunicación y el mínimo acercamiento de las docentes hacia sus estudiantes, lo que entorpece el aprendizaje eficaz. Estar cerca de ellos, establecer una interconexión con sus inquietudes y proporcionar un ambiente de confianza, seguridad, diálogo e intercambio permanente, son elementos esenciales que contribuyen a la adquisición de conocimientos.

Cabe destacar que en pleno siglo XXI se ubica una nueva dimensión escolar, en donde el espacio no debe limitarse a los pupitres y al escritorio del docente, sino a un espacio abierto, flexible y cálido para que el estudiante logre una aprehensión exitosa de la situación de aprendizaje.

De ahí precisamente el papel del docente debe centrarse en una interacción sistemática y permanente con los estudiantes. Esta interacción facilitará la conceptualización, la reflexión y la resolución de problemas. Asimismo, el desarrollo intelectual del educando no depende de una simple acumulación mecánica de información, sino que requiere de un intercambio dinámico con su profesor y con sus compañeros.

En el elemento b: la enseñanza de la literatura, se encontró que las docentes no articulan o relacionan los objetivos con los contenidos del plan de estudios de Español, planteado por el MEP. Se observó que las docentes poseen una preocupación constante por cubrir los contenidos (leer el texto, saber cuál es el autor, el narrador, el género y movimiento literario, personajes, código apreciativo) y no le toman importancia a la participación y aportes de sus estudiantes; tampoco buscan cumplir con el objetivo esencial de la literatura que es establecer su carácter dialógico y la multiplicidad de significados.

Lo que llama poderosamente la atención es que, aunque el MEP establece que la corriente que debe guiar la enseñanza del Español es el aprendizaje significativo, el que se aplica es el conductismo. En las clases observadas el contenido sigue siendo más importante que el 
objetivo, como consecuencia se realiza una sola lectura del texto literario y el análisis que se propone; en lugar de tomar en cuenta los elementos históricos, sociales y culturales, enseña el texto de manera fragmentaria, ya que solamente interesa conocer quién escribió la obra, cuál es el narrador, establecer el tiempo y responder ciertas preguntas de comprobación de lectura.

En una de las observaciones realizadas, mientras los estudiantes completaban una de las guías de análisis del texto "El Gato Negro" de Edgar Allan Poe, se encontró que los alumnos querían participar pero la profesora no tomó en cuenta sus intervenciones porque consideró que se desviaban del análisis en cuestión. Sin embargo, los estudiantes comentaron sobre una serie de televisión llamada "CSI Las Vegas", en la cual se resuelven casos de asesinatos. Los estudiantes muestran interés por este programa y realizan una asociación significativa entre la trama del cuento y la forma en que se esclarecen los misterios de asesinato en la serie de televisión, ya que al igual que en el cuento, al final, el lector y el televidente son los únicos que conocen cómo se llevó a cabo el crimen.

Las intervenciones de los estudiantes van encaminadas a compartir historias de familiares que guardan relación con el licor y la violencia; pero son interrumpidas por la profesora, quien señala que "no deben salirse del tema".

La descripción anterior evidencia que los estudiantes, además de buscar referentes cuando leen, son capaces de realizar lecturas y asociaciones entre el texto y su realidad. Están anuentes a participar, pero la profesora es quien guía el análisis, dejando de lado sus intereses y los objetivos planteados. Como consecuencia, los alumnos se limitan a escuchar, a seguir la lectura y a participar si así lo considera pertinente la docente.

De esta manera, aunque los aportes de los alumnos provienen de sus realidades cotidianas y desean expresar su opinión, la profesora les señala volver al análisis formal y estilístico del texto literario, sin relacionarlo con la realidad.

No cabe duda que el análisis literario que realizan las docentes se centra en cubrir los contenidos que contempla el Ministerio de Educación Pública en los programas de estudio de Español, los cuales, a la vez, se abocan por analizar el texto literario, tomando en cuenta elementos estilísticos del texto y no aquellos que le permiten al estudiante fortalecer sus habilidades de lectura, análisis y reflexión.

Por las razones anteriores el objetivo básico, que es despertar la sensibilidad y el placer por el texto, se pierde. El análisis literario deja de lado las relaciones que muestra el texto con el entorno del alumno, se reducen y se simplifican a la memorización de categorías de análisis que los estudiantes no comprenden, además, se esconden las condiciones de diálogo, lo que provoca que el educando vea una sola realidad sin derecho a establecer inferencias y criterios, así como la posibilidad de que logre desarrollar una conciencia histórica y cultural. Estos aspectos anulan en el educando su capacidad de distinguir más allá de la apariencia e iniciar una búsqueda hacia nuevos conocimientos que integren su pensamiento.

Con respecto a los programas de estudio, las docentes no incluyen contenidos de literatura que orienten el acercamiento del estudiante a los textos y, por otro lado, olvidan los objetivos de enseñanza, los cuales señalan que: "El estudiante debe reconocer la lengua literaria como un sistema ficcional, connotativo, plurisignificativo, dialógico cultural, además, que la comprensión de todo texto implica una competencia del lector como sujeto participante, para enriquecer su actividad de percepción y de descriframiento", y se apoderan del contenido formal como única vía de conocimiento. 
Silvia Méndez Anchía (2000: 96) coincide al señalar que:

\begin{abstract}
El docente no puede enfocar de manera novedosa y viva el estudio de la literatura, pues debe cubrir los contenidos que se evaluarán en las pruebas estandarizadas nacionales, que pueden ser aprobadas por el estudiante con sólo mencionar los comentarios de especialistas, sin tener contacto directo y personal con las obras literarias.
\end{abstract}

Es así como los contenidos de literatura se limitan a caracterizar géneros literarios, figuras retóricas y categorías de análisis. Se olvida la interpretación y el análisis literario se reduce a aspectos de estilo que el estudiante debe memorizar para el examen.

Al respecto, Sonia Marta Mora (1986: 34), en el libro La palabra al margen, la enseñanza del español en crisis, señala que bajo las condiciones antes descritas, la literatura:

\footnotetext{
Resulta ser un campo aislado, vaciado de toda significación humana. De ahí que los conceptos que orientan el estudio de la literatura propicien una visión ahistórica, estática y fragmentaria del objeto. Esta manera de acercarse a la literatura no sólo la reduce claramente, sino que desaprovecha elementos imprescindibles para el disfrute y la verdadera comprensión de este quehacer y sus productos.
}

En este sentido, a través de las observaciones hechas a las docentes en el aula, se encuentra una desarticulación o bien una contradicción entre objetivos y contenidos que se plantean para analizar el texto literario, además de una metodología guiada por el enfoque conductista y no por el aprendizaje significativo.

Los estudiantes leen desmotivados ya que conocen, de antemano, la manera en que analizarán el texto literario: repiten las mismas tareas, mientras la docente se debate en cumplir con el objetivo o con el contenido; finalmente elige el último, ya que debe prepararlos para las pruebas que realizarán durante los cinco años de permanencia en el colegio.

En el tercer elemento: tareas para abordar el análisis literario, se observó que la dinámica para analizar un texto literario es la siguiente:

1. Los alumnos deben leer el texto en la casa.

2. En las lecciones de Español, la docente comenta brevemente el argumento del texto y algunos aspectos de vocabulario. Solicita a los estudiantes que realicen la guía de análisis del libro de texto.

3. Al finalizar deben empezar otra guía en el cuaderno facilitada por las profesoras al inicio del curso lectivo.

4. Terminadas estas guías, la docente se dispone a revisar oralmente las respuestas, con el propósito de unificar criterios para efectos de la evaluación.

5. Finalmente, pasa por cada pupitre o llama a cada estudiante al escritorio para sellar y firmar las guías completas, si no están completas no hay firma ni sello, lo que significa que no hay puntos de trabajo cotidiano.

Las tareas mencionadas anteriormente se realizan con todos los textos literarios, sin importar que uno pertenezca al movimiento literario del Realismo o del Modernismo. Sin detenerse a contextualizar cada uno, según su época y sus características particulares. Se realizan las mismas preguntas para dos géneros y dos épocas diferentes. De esta manera, a los estudiantes se les dificulta comprender los textos, dialogar con ellos, establecer asociaciones y procurar una competencia como lectores. Esta dificultad radica en que aún no se les ha permitido realizar un análisis literario que disfruten y en el cuál adquieran destrezas interpretativas que puedan aplicar cada vez que leen. 
En este sentido, Ovares (1986: 31) señala que el alumno no participa construyendo su aprendizaje, ya que en el análisis que debe realizar repite las mismas actividades en cada unidad, sin tomar en cuenta la particularidad del tema tratado y la acumulación de sus experiencias como estudiante.

Debido a la condición en la que se analiza el texto literario, la motivación y desempeño de los estudiantes son bajos. Están pendientes de los puntos que deben ganar para el trabajo cotidiano con la resolución de la práctica, más que de analizar el cuento.

Por eso, no existe un progreso por parte de los estudiantes en los procesos de síntesis, profundización y abstracción de los textos literarios, ya que se presenta una adición o repetición de elementos que le confieren una posición propia del conductismo: el alumno solo recibe sin saber por qué y el profesor imparte el conocimiento por el conocimiento.

Esta dinámica de clase genera en los alumnos desmotivación ya que es sometido a resolver dos guías de análisis prácticamente iguales sin detenerse a pensar por qué debe resolverlas y para qué, es decir, aún resolviéndolas no es capaz, la mayoría de las veces, de comprender el texto literario.

Es así como los alumnos repiten el análisis, están interesados en contestar la práctica, sin contemplar la posibilidad de análisis e interpretación del texto literario. Como consecuencia, el análisis literario se pierde en la identificación de personajes, fechas y acontecimientos.

Un ejemplo de esta situación se muestra cuando, en el proceso de revisión de una de las guías para analizar la crónica "Las carreras de San Juan", los alumnos comentan sobre la dificultad para comprender el vocabulario del texto, y como resultado no logran profundizar en los otros niveles de lectura. Cuando la profesora les pregunta cuál es el final del texto, ninguno responde. Este ejemplo sugiere que si los estudiantes preguntan sobre el vocabulario, no están comprendiendo el texto a nivel literal y se les exige un análisis literario sin clarificar pasos vitales para acercarse a un texto literario. Por lo tanto, se quedan en una lectura superficial del texto.

El último elemento es el tipo de lectura que realizan los estudiantes. Sin embargo, se observó que la docente es quien lee y quien interpreta. Su lectura es la misma que la del libro de texto y desea que la lectura de los estudiantes sea esta también. En esta línea, no hay otras posibles lecturas, la idea de plurisignificación y de dialogismo se aparta para dar lugar a una única lectura.

De este modo, la docente se asegura una evaluación homogénea y la revisión oral de la práctica posee el propósito de unificar criterios para evaluar.

Por ejemplo, el estudiante en el libro de texto Tiempo de leer desarrolla la siguiente tarea: Explique tres características del Romanticismo presentes en "Las carreras de San Juan". Cite ejemplos.

Luego debe realizar la misma tarea en la guía que facilita la profesora en el cuaderno: Cite tres características del movimiento literario al que pertenece el texto.

Esta guía de análisis, según información suministrada por la profesora, es facilitada a los estudiantes al inicio del año, ya que deben realizarla después de finalizar con la otra guía del libro de texto y con todos los textos que se leen.

Ambas guías de análisis fueron comparadas y revisadas. Se encontró que las dos son prácticamente iguales en sus cuestionamientos; por esta razón, puede observarse que contestar las mismas preguntas resulta para el estudiante una dinámica rutinaria y repetitiva, debe realizar tareas exactamente iguales, en las cuales se omiten elementos que podrían despertar su interés y la adquisición de nuevos conocimientos. Vistas así las cosas, se somete al estudiante a un trajín abrumador en el que no produce, no expresa y no construye, solamente es un receptor 
pasivo que debe realizar dos veces la misma lectura, la del libro de texto y la que facilita la docente. Contrario a lo que pretende el objetivo del plan de estudios: que el estudiante sea poseedor de una competencia como lector y disfrute de la lectura.

En este sentido, el análisis del texto literario se resume en el empleo de la presencia estilística como concepción teórica y metodológica básica. Lo importante es que el alumno maneje conceptos como el de narrador, espacios, tiempo, código apreciativo, entre otros. Como resultado de esta dinámica, los efectos sobre el análisis textual son desalentadores, en la medida en que el estudiante se ve limitado a explorar el texto literario a través de otras lecturas que posean más significado para él y se relacionen con su entorno y sus vivencias.

Es así como el objetivo de enseñar literatura, según Lomas (2005), radica en poner en claro el carácter dinámico de los textos, los cuales se insertan en procesos históricos y abren otras posibilidades de lectura.

Es por ello que los estudiantes consideran repetitivo cada análisis que realizan, los ejercicios se restringen a la memoria, a la repetición y a actividades mecánicas, así surge la desmotivación y la pérdida de interés por la materia.

Por otra parte, según lo que se observó, se presenta un manejo equivocado del libro de texto, ya que no funciona como un instrumento auxiliar o como una propuesta alternativa para analizar el texto, sino que en él se centra todo el desarrollo de la clase. La problematización de los textos se descarta, no se fomentan las operaciones mentales que trascienden lo reproductivo ni se da cabida a un pensamiento divergente, el cual podría generar un clima de gusto y aprecio por la literatura. Como señaló Silvia Méndez (1999: 238), "En ocasiones el libro de texto sustituye al programa de estudios y conforma el verdadero currículo con que trabajan profesores y alumnos".

Así, el libro de texto utilizado en estas clases responde a una metodología pasiva en la que no se establece un diálogo entre el estudiante y el texto literario, además, es concebido por la docente como la única actividad por realizar en clase. Estos elementos repercuten negativamente en el proceso de enseñanza-aprendizaje de la literatura, entorpecen el desarrollo de una metodología activa en la que el estudiante podría disfrutar del texto, si realiza diferentes lecturas en las que predomine un afán lúdico, la expresión de la creatividad, la imaginación y el juicio crítico, a través de sus experiencias como estudiante. En este sentido se muestran dos problemas: el tipo de libro de texto y el uso que hace el docente de él.

\subsection{Conversando con los estudiantes}

Uno de los principales propósitos de la investigación que se realizó fue establecer una conversación directa, abierta y flexible para que los estudiantes expresaran sus ideas u opiniones con respecto al acercamiento que experimentan hacia la literatura y al análisis de textos literarios.

A través de las entrevistas que se realizaron al estudiantado con la intención de conocer las nociones que poseen con respecto a la definición del término literatura y del análisis literario, en las respuestas no se encontró una definición del término, sino que se centraron en nombrar géneros literarios y figuras literarias. Para ellos la literatura se relaciona únicamente con géneros literarios y nombran dos específicamente: cuento y poesía; dejando de lado la novela y el ensayo, ambos también géneros literarios. Sobre el cuento afirman que les gusta pero la poesía no. Señalan que el género lírico es aburrido y complicado, no por el poema en sí, sino por las tareas que deben hacer para su análisis. 
Como vemos, en ningún momento se define qué es literatura o cuáles son sus características; para los estudiantes, literatura es análisis, esto implica, en el caso de la poesía, análisis estilístico: encontrar métrica, rima y figuras literarias. Tampoco hablan del sentido del texto o de la interpretación y lectura que cada uno realiza cuando lee. No se refieren al proceso de leer, sino al análisis literario que les imponen las docentes al estudiar el tema.

En este sentido, los estudiantes consideran a la literatura como un conocimiento que requiere un acercamiento formal y de estilo. Según sus respuestas, el texto literario no es aún concebido como un pacto literario entre él, como lector, y el libro, y que este intercambio lo puede proveer de ideas, de sentidos, de asociaciones y el desarrollo de sus capacidades como lector, sino que sigue viendo el texto literario sólo a través de criterios estrictamente académicos: presencia de fechas, nombres y categorías de análisis; sin detenerse a comprender que a través de la lectura, se favorece tanto el contrato comunicativo entre el autor y el lector al que el texto invita, como, en consecuencia, la comprensión y el disfrute de la obra.

Los aspectos antes mencionados demuestran que, para los estudiantes, la literatura es análisis formal del texto y requiere de conocimientos específicos que sólo se aprenden en el colegio. En ningún momento hablan del placer de leer o bien del proceso de comunicación que cumple la literatura.

Una de las preguntas que se les planteó fue ¿Cuáles géneros literarios prefieren? Respondieron que les gustaba el cuento ("El gato negro"). La predilección de los estudiantes por el género cuento, manifiesta su interés por temas actuales o bien, aquellos que se relacionan con su realidad cotidiana. Esto muestra la necesidad de un referente para acercarse al texto literario. Las temáticas de la violencia, el alcoholismo, entre otras, forman parte del contexto social en el que se desenvuelven los estudiantes y al presenciar temas que conocen, se genera el atractivo del texto. En este sentido, el educando asimila nuevos conceptos, en la medida en que esas nuevas nociones se relacionan con sus intereses próximos, y a través de los conocimientos que ya posee, tiene la capacidad de adquirir nuevos y relacionarlos con los que ya conoce, es así como logra la discriminabilidad del material de aprendizaje y lo integra a su estructura cognoscitiva.

Así lo señala Ausubel (1981: 187):

(...) La eficacia del aprendizaje significativo radica en relacionar, intencionalmente, el material significativo con las ideas establecidas de la estructura cognoscitiva del estudiante; es decir, la manera en que es posible emplear las ideas previamente aprendidas en el procesamiento de ideas nuevas consiste en relacionarlas intencionalmente con las primeras. Las ideas nuevas, que se convierten en significativas, expanden también, a su vez, la base de la matriz de aprendizaje.

Con respecto al texto literario, se les preguntó ¿Qué es lo que consideran más importante de él? Los estudiantes respondieron que lo más importante era la enseñanza que les podía dejar. Las respuestas a esta pregunta muestran que los estudiantes establecen una relación del texto literario como medio de enseñanza. Es decir, el texto, ante todo, debe poseer una moraleja que los enseñe a conducirse adecuadamente en la sociedad.

De este modo, se ve la literatura como un hecho de educación moral y se olvida su función que es entretener, adquirir conocimientos, explorar nuevos mundos, ejercitar la imaginación y el ser críticos como lectores.

Es posible que este pensamiento de leer el texto para extraer una enseñanza se genere en la formación literaria que los estudiantes reciben en la educación primaria, en donde la maestra lee un cuento y luego pregunta qué enseñanza les ha dejado. Es así como ingresan a secundaria y adoptan esta manera de ver la literatura y cuando se enfrentan a la propuesta de realizar análisis literario, este se limita a nombrar enseñanzas, personajes y acontecimientos. 
Con las respuestas a esta pregunta se visualiza que la enseñanza que reciben los educandos para analizar los textos literarios no sólo se centra en los elementos formales del texto sino que se guía la lectura a un enfoque moralizante de la literatura. Es así como este enfoque provoca actitudes hostiles por parte de los alumnos ante lo literario, es decir, leen como les indica la profesora, no es posible otra lectura en donde la libre expresión y las actitudes creativas y críticas sean protagonistas en este proceso.

Los elementos antes expuestos demuestran que el ingreso de los alumnos a la literatura propuesta para sétimo año no se relaciona con la idea de literatura con la que han tenido contacto durante la educación primaria.

Según Méndez Anchía:

\begin{abstract}
La enseñanza media considera que el estudiante, durante el período de la primaria, adquiere todas las habilidades de lectura necesarias, sin embargo, se le enseña un tipo de lectura expresiva y recreativa, por lo que al llegar a secundaria se ve limitado ante el análisis literario dictado por el Ministerio de Educación Pública, que debe realizar como si fuera todo un filólogo (2000: 91).
\end{abstract}

Esta situación destaca que en el plan de estudios de Español propuesto por el MEP no se establece un período introductorio que forme a los estudiantes en el campo literario y, como consecuencia, estos se quedan con la idea de que lo importante de todo texto literario es lo que pueda enseñar, sin pensar en cómo lo pueden disfrutar. De esta manera, no se da un proceso gradual de cambio entre la literatura infantil y la literatura que se lee en secundaria, sino que los estudiantes inician con el estudio de clásicos de inmediato. En sétimo año inician su acercamiento con la novela Marianela, obra realista del siglo XIX, del escritor Benito Pérez Galdós; y en primaria leen Pantalones cortos, Cocorí, entre otras.

Estas circunstancias limitan las experiencias que los estudiantes pueden desarrollar en un campo tan vasto como la literatura en donde, a través de la identificación con el mundo enunciado en el texto literario, encuentran mundos posibles, puntos entre la ficción y la realidad, entre la experiencia literaria a la que invitan y la experiencia de lo cotidiano; así como enfrentarse a estereotipos, ideologías, estilos de vida y maneras de entender y cuestionar el mundo.

De esta manera se presenta por parte de los alumnos una búsqueda por el valor moral del texto, y dejan de lado el disfrutar de la lectura, analizar qué elementos se cuestionan, identificar qué características poseen los personajes y de qué manera se relacionan con su contexto social, cultural y psicológico.

Es notable que el texto literario se convierte, para los estudiantes, en un campo al que accesan con el propósito de encontrar una enseñanza. La parte interpretativa, creativa y placentera del texto literario se pierde. Estos datos permiten inferir que el estudiante no es consciente de lo que aprende, pues, bajo un enfoque conductista, debe aprender a realizar iguales tareas sin cuestionarse por qué, y sus motivaciones y actitudes internas no se toman en cuenta. En este sentido, la información que se considera importante de suministrar es la de los contenidos, la evaluación y la memoria, pero no el significado de lo que se enseña.

Por otra parte, a la pregunta ¿Qué opinan de las clases de español? Respondieron que las clases eran aburridas y poco participativas. Uno de los estudiantes señaló: "A veces es muy cansado y es muy sofocante” (Ramírez 2007: 109).

Ante las respuestas de los estudiantes, Ovares, en el libro La palabra al margen, la enseñanza del español en crisis, del año 1986, señala que durante esta época el conductismo configura la concepción educativa que orienta los procesos de enseñanza del Español en el país y resume algunas de las consecuencias de este enfoque en la enseñanza del Español. Esta autora señala que este tipo de enseñanza se impone desde fuera, organizada según estructuras 
lógicas pero no psicológicas, como consecuencia el estudiante no aprende pues responde a una sucesión de estímulos, en los que no juega ningún papel su estructura activa.

Tomando en cuenta esta explicación puede observarse que, aunque el Ministerio de Educación Pública haya adoptado otro enfoque en la elaboración de objetivos para la enseñanza del Español, en este caso el aprendizaje significativo, los contenidos del año 1986 al año 2006 siguen aún una línea conductista, ya que la lectura que las docentes observadas hacen del programa continúa centrándose en el conductismo.

De acuerdo con lo anterior, se infiere que las docentes observadas ejecutan un inadecuado proceso metodológico para acercar a los estudiantes a la literatura. Por esta razón, los alumnos señalan que la clase es aburrida, ya que gira en torno a la repetición de temas y conceptos en donde su pensamiento y sus intereses no intervienen. Coinciden en que la clase es pasiva y les gustaría que eso cambiara. También, sugieren más dinamismo y manifiestan su necesidad e interés por participar y ser incluidos en la actividad de clase. En este sentido, no están de acuerdo con las conductas de silencio absoluto, en donde la profesora habla y ellos escuchan, la profesora sabe y ellos no.

Con respecto al uso del libro de texto, se les preguntó ¿Qué opinan sobre el libro que utilizan en clase? Los estudiantes expresaron que sí utilizan el libro de texto pero no todos lo disfrutan. Por ejemplo, uno de los entrevistados considera que el libro no es aburrido, sin embargo, señala la palabra esfuerzo en su respuesta, se infiere que este estudiante utiliza el libro de texto pero representa un esfuerzo para él.

Estas respuestas permiten visualizar que existe una aceptación de los estudiantes por el libro de texto, consideran que les facilita la comprensión del texto literario, sin embargo, no los motiva pues las tareas que realizan diariamente en el libro son siempre las mismas: leer el texto literario, leer el análisis literario y responder las preguntas de la práctica. En esta línea, el estudiante no investiga, no construye el conocimiento debido a la dependencia que le genera el uso del libro de texto.

Al analizar las respuestas, se evidencia que no existe una mediación por parte del docente entre el libro de texto y el estudiante. Esta situación convierte al libro de texto en sustituto del currículo que debe desarrollarse en la clase. Este hecho reafirma lo que Silvia Méndez (1999: 10) señala al expresar que el libro de texto es utilizado por los docentes y estudiantes como la única vía de conocimientos, esto genera que no se construya el aprendizaje.

También puede inferirse que el libro de texto representa una obligación y un esfuerzo para el estudiante y se plantea no como un instrumento de consulta, sino como el centro y único fin en la clase.

Los estudiantes afirman que el texto literario no solamente se comprende al responder las prácticas del libro de texto, sino también a través de las explicaciones de la profesora. Estas opiniones reflejan una dependencia significativa de los estudiantes con el libro de texto y con la profesora para comprender el texto literario. Es decir, si no comprenden el texto literario consultan el análisis que ya está hecho en el libro de texto y si aún no entienden recurren a la docente.

Debido a lo planteado anteriormente, las preguntas que surgen son: ¿En qué momento el estudiante participa en la construcción del conocimiento? ¿Cuál es el espacio que se nutre para que los alumnos reflexionen, cuestionen e interpreten? ¿Si el libro de texto y el aporte de la profesora suplen ese espacio, en qué momento el estudiante es consciente de su aprendizaje? 
En este sentido, el estudiante no ha tenido la oportunidad de conocer que la lectura del texto literario no solo puede ser interpretada por el libro de texto y la docente sino que su lectura es válida y la de sus compañeros también. Es evidente que no saben que el análisis es una interpretación del texto literario y que lo importante es su carácter plural, connotativo y multisignificativo.

\subsection{Conversando con las docentes}

Al igual que en la entrevista de los estudiantes, se les preguntó a las docentes ¿Qué consideran que es la literatura? Ante esta pregunta una de ellas respondió que la literatura es "la manifestación de sentimientos, ideas y temas sociales que inquietan a un escritor y éste los plasma en una obra" (Ramírez 2007: 125). A través de esta respuesta la docente sugiere que la literatura es el medio por el que un escritor expresa sus sentimientos, ideas, inquietudes y finalmente, quien logra revelarlas en una obra.

En este caso la profesora define la literatura desde un criterio de autoridad, el cual señala que la categoría organizadora privilegiada es la de autor, como individuo creador, a partir de la cual puede leerse que la literatura es entendida como expresión, casi privada, de un sujeto personal. En esta línea se estaría dejando de lado al lector y sus conocimientos previos, la relación de diálogo e intercambio que se establece entre el lector y el texto quedan desprovistos de toda importancia.

En este sentido el carácter dialógico y plurisignificativo de la literatura no es concebido por las docentes, la literatura se vuelve un pretexto del trabajo didáctico que se sustenta en un autor que escribe y en un lector pasivo que lee sin que se establezca ningún intercambio.

Como consecuencia, tanto el educador como el educando no poseen una definición amplia y clara del término literatura, el enseñarla y aprenderla se limita al criterio de que alguien escribe y alguien lee. En este caso el estudiante, sin comprender el porqué es importante leer, interpretar y establecer intercambios que le permitan acercarse a otras ideas y pensamientos, se convierte en un lector pasivo.

Un ejemplo claro son algunas expresiones de los estudiantes: "nos gustan algunos textos que leemos como el Gato Negro, pero no nos gusta la poesía, la rima, la métrica, las figuras literarias", "la literatura es aburrida porque solo leemos y tenemos que hacer las prácticas del libro", "la profesora explica pero a veces es aburrido" (Ramírez 2007: 109).

A través de estas expresiones se visualiza que a los estudiantes sí les gusta la literatura, y lo que les disgusta es la forma como es enseñada, debido a que la docente es quien asume el protagonismo. Según su respuesta, aunque no les guste leer, ella asume la lectura, la explicación y el análisis del texto literario.

Es así como la literatura se traduce en una actividad obligatoria y programada por el docente. El estudiante escucha, copia y repite.

El nivel de actividad cognitiva por parte de los alumnos no se desarrolla, la docente es quien resuelve todos los posibles conflictos cognitivos que se presenten, y el alumno es un ente pasivo ante el conocimiento y el desarrollo de sus habilidades cognitivas. En esta línea, se promueve el aprendizaje memorístico y receptivo, que consiste en aprender la información de manera literal y adquirir productos acabados de información, donde el alumno sólo internaliza los datos en cuestión. 
Según Méndez (2000), se reconoce que el conductismo aplicado a la educación ha conformado una fuerte tradición dentro de la psicología educativa, desde los primeros escritos de Skinner hasta la actualidad. Al respecto, señala:

\footnotetext{
El influjo del conductismo en educación ha sido grande, y ha hecho que el maestro se preocupe por planificar su enseñanza(...) Sin embargo, su énfasis en los condicionamientos, en establecer científicamente las correlaciones entre determinados estímulos específicos y las respuestas que provocan en los sujetos experimentales, ha inducido erróneamente a algunos educadores a olvidar que el proceso de enseñanza-aprendizaje, en el ser humano, va más allá de esto (Méndez 2000: 17).
}

Por otro lado, el propósito de preguntar a las docentes ¿Cuáles estrategias metodológicas utilizan para analizar el texto literario y si ese método resulta efectivo?, se orienta a determinar cómo enseñan y cómo el alumno percibe esta enseñanza.

Si se observa la manera en que una de las docentes expresa cuáles estrategias metodológicas utiliza, se muestra que es ella quien se da a la tarea de asumir ciertos pasos para analizar, por ejemplo, al referirse al texto literario, señala: “yo lo leo, lo comento, lo relaciono con la realidad, le saco alguna enseñanza y los pongo a trabajar" (Ramírez 2007: 126). Estas expresiones sugieren que el protagonismo en el proceso de enseñanza-aprendizaje no es de los estudiantes, ellos únicamente trabajan lo que ya fue argumentado, interpretado y analizado por la docente y por el libro de texto.

Estos datos permiten inferir que la dinámica de clase consiste en que la profesora comente el texto, explique algunos significados léxicos y que los alumnos recurran al libro de texto para resolver la práctica, revisarla oralmente con la docente y, finalmente, realizar la otra práctica en el cuaderno.

Esta situación trae a la luz algunas de las opiniones emitidas por los estudiantes en las entrevistas, que se centran en afirmar que cuando la profesora explica es mejor para ellos, ya que solo se preocupan por resolver las prácticas. Asimismo, conciben el texto literario como un espacio de moralejas, es decir, el texto ante todo debe enseñar algo, no piensan en el texto para disfrutar, para cuestionar o relacionar. Por esta razón, los alumnos expresan que las clases de español se tornan aburridas, los pasos para acercarse al texto son siempre los mismos y la dinámica impuesta por la docente no les permite ser protagonistas en la adquisición de conocimientos.

Por otra parte, con respecto al uso del libro de texto, las docentes consideran que en él está la información necesaria para guiar a los estudiantes en el análisis, incluso a aquellos que no leen el texto literario. Tomando en cuenta esta apreciación, los estudiantes también señalan que el libro de texto es una ayuda, es decir, existe una aceptación de los estudiantes por este, pues consideran que les facilita la comprensión del texto literario; sin embargo, es evidente que su valoración del libro radica en que este contiene toda la información que necesitan saber para realizar el examen. También plantean que el libro de texto representa una obligación y que en la clase de Español la única actividad por hacer es llenar las prácticas.

De este modo, aunque la docente considere que ha dotado de herramientas a sus estudiantes para analizar textos literarios, se ha limitado a la mera ejecución técnica del programa de estudios y a la transmisión verbal de los contenidos académicos de la asignatura.

Asimismo, a pesar de que el MEP haya implantado en el programa la corriente del aprendizaje significativo, la situación que se encuentra, en este caso, resulta paradójica: mientras los documentos programáticos declaran su opción por una enseñanza de la lengua y la literatura comunicativa y funcional, las pautas metodológicas y los contenidos de la enseñanza 
siguen siendo muy parecidos a los tradicionales; se ve reflejado en el libro de texto que utilizan y en la manera en que dominan las prácticas de la enseñanza.

Al quedar en evidencia esta realidad, se puede señalar que la aplicación del programa de estudios de Español y las estrategias metodológicas utilizadas por las docentes para analizar los textos literarios, no promueven situaciones donde la literatura se vea arropada por su verdadera función social y cultural, impulsando la participación activa de los estudiantes en actos de intercambio que tengan propósitos explícitos.

\section{Conclusiones}

A través del análisis de la información obtenida en las observaciones y entrevistas realizadas a docentes y estudiantes se llegó a las siguientes conclusiones:

\section{a- De los estudiantes:}

- En las entrevistas a los estudiantes se encontró que éstos pasan de la enseñanza primaria a la secundaria desprovistos de conocimientos con respecto a la literatura, sus funciones y características. De acuerdo con sus respuestas se puede inferir que los estudiantes no poseen conocimientos básicos sobre el término; para ellos, la literatura es análisis estilístico: encontrar métrica, rima y figuras literarias. Se les ha enseñado como literatura análisis formal del texto.

Esta situación demuestra que los estudiantes poseen una concepción limitada y ambigua de lo que es literatura. Se limitan a considerarla como el género y el análisis literario. Para ellos, la literatura se restringe a esos términos y según sus opiniones, esta no es concebida como placentera sino como una tarea por cumplir.

- No puede afirmarse que a los estudiantes no les gusta la literatura, sino que les aburre la forma en que es enseñada. A pesar de esto, se encontró que los estudiantes, además de buscar referentes cuando leen, son capaces de realizar lecturas y asociaciones entre el texto y su realidad.

- En las observaciones de aula que se realizaron, se muestra que los alumnos siempre están sentados en hileras, deben hacer silencio y cumplir con las mismas tareas del libro de texto. Por esta razón, los educandos claman por más dinamismo, manifiestan su necesidad e interés por participar y desean ser incluidos en la actividad de clase.

- Los estudiantes expresan que cada análisis que realizan es repetitivo, porque deben cumplir con las prácticas del libro de texto y además, con la guía de preguntas en el cuaderno, que facilitan las docentes.

- La clase de Español se limita a escuchar y leer el análisis literario de la profesora y el que está en el libro de texto; se les pide a los estudiantes repetir los contenidos sin posibilidades para desarrollar su habilidad para la interpretación, libertad de opinión con respecto al medio, capacidad para formular, probar y valorar hipótesis, lo que genera una educación bancaria, según la terminología desarrollada por Freire. 


\section{b- De los docentes:}

- Existe una preocupación de las docentes por cubrir los contenidos. Esta preocupación se centra en evaluar para sacar una buena promoción, es decir, enseñar para el examen. Con esta preocupación no se cumple con el objetivo esencial de la literatura propuesto por el MEP y además propio del acto de la lectura: que es establecer su carácter dialógico y la multiplicidad de significados, sino que las docentes se abocan por analizar el texto literario tomando en cuenta elementos estilísticos del texto y no aquellos que le permiten al estudiante fortalecer sus habilidades de lectura, análisis y reflexión del texto literario.

- La práctica contenedista de las docentes impide una relación entre los contenidos y los objetivos; incluso en las entrevistas se observa que las definiciones que dan del término literatura no son estructuralistas y menos sociocríticas, son estilísticas. En este sentido aunque los objetivos sean sociocríticos la aplicación de los contenidos no posee esta consigna.

- El educador y el educando no poseen una definición amplia y clara del término literatura, ya que el enseñarla y aprenderla se limita al criterio de que alguien escribe y alguien lee, en este caso el estudiante lee sin comprender el porqué es importante leer, interpretar y establecer intercambios que le permitan acercarse a otras ideas y pensamientos. Ambos poseen una concepción muy limitada y ambigua de la literatura y del texto literario.

- A través de las conversaciones con los alumnos, se puede inferir que no realizan análisis literario, aunque la docente considera que sí. En esta línea, se manifiestan tres apreciaciones diferentes de lo que es un análisis literario: para los estudiantes es responder las preguntas de la práctica del libro de texto y del cuaderno; para las docentes, el análisis del texto literario se resume en una revisión estilística. Para ellas, lo importante es que el alumno maneje conceptos como narrador, espacios, tiempo, código apreciativo, entre otras; y para el MEP, en el planeamiento de los objetivos, el análisis literario es dialogar con el texto desde una postura sociocrítica.

Estas diferentes visiones demuestran que existe una desarticulación entre lo que el MEP plantea en el programa de estudio, lo que los docentes interpretan de ese programa y lo que reciben los estudiantes como análisis literario.

\section{c- Del libro de texto}

- Según se observó en todas las entrevistas y observaciones debido a las limitaciones en la mediación pedagógica, se presenta un manejo equivocado del libro de texto, ya que no funciona como un instrumento auxiliar o como una propuesta alternativa para analizar el texto, sino que en él se centra todo el desarrollo de la clase.

En este sentido, según los aportes de Marta Rojas (1998), Alonso Ramírez (1997) e Isabel Gallardo (2001), la problematización de los textos se descarta, no se fomentan las operaciones mentales que trascienden lo reproductivo ni se da cabida a un pensamiento divergente, el cual podría generar un clima de gusto y aprecio por la literatura.

Por esta razón no existe una mediación por parte del docente entre el libro de texto y el estudiante. Esta situación lo convierte, como lo mencionó Silvia Méndez Anchía, en sustituto del currículo que debe desarrollarse en la clase. El libro de texto es utilizado por la docente como el único recurso para enseñar, a través de él se realizan todos los análisis literarios. 
En este sentido, el libro de texto se utiliza como la recopilación de todas las certezas y representa una respuesta segura a cualquier pregunta posible, tanto para el docente como para el estudiante.

\section{d- De la enseñanza:}

- A través de las observaciones y entrevistas a los estudiantes se encontró que todos los textos literarios se analizan igual: sin importar que uno pertenezca al Romanticismo y otro al Modernismo, o uno al género literario cuento y el otro al género lírico.

La guía de preguntas que facilita la docente es la misma para cada texto literario aunque la época y el contexto sean diferentes. Según Sonia Marta Mora, esta situación es producto de analizar el texto de forma fragmentaria y no como un todo que dialoga. Esta dinámica demuestra que existe una mala lectura del programa de estudio, por parte de las docentes debido a que se evidencia una desarticulación entre objetivos y contenidos para analizar el texto literario, además de una metodología guiada por el enfoque conductista y no por el aprendizaje significativo.

- Asimismo, la falta de un ordenamiento metodológico, tanto en el nivel de los conceptos como en términos de los contenidos programados, puede impedir que el estudiante se relacione directamente con el objeto de estudio, ya que ofrece temas alejados de sus intereses vitales o conceptos que no significan un reto para sus estructuras cognoscitivas en proceso de desarrollo. También la metodología empleada por las docentes imprime un carácter unidireccional en la enseñanza, ya que el aprendizaje no es sólo la adquisición de técnicas instrumentales y de destrezas básicas, sino también el resultado de procesos de interpretación y de comprensión que faciliten la construcción por parte del alumno.

- Existen grandes vacíos metodológicos ya que el objetivo planteado por el MEP señala que el estudiante debe "reconocer la lengua literaria como un sistema ficcional, connotativo, plurisignificativo, dialógico cultural, y, además, que la comprensión de todo texto implica una competencia del lector como sujeto participante, para enriquecer su actividad de percepción y de descriframiento" (MEP 2005: 25).

Sin embargo, se evidencia que entre el programa planteado para la enseñanza del Español y lo que sucede en realidad en las aulas existe una gran distancia. Si bien se pretende que el estudiante logre comprender la importancia de la lengua literaria, lo que hace en la clase es recibir tareas de lectura centradas en el texto, aprender cómo se contestan preguntas, realizar un examen, hacer un esquema o un resumen y, además, repetir, y parafrasear, de forma parcial o total, la información.

- A través del análisis realizado se evidencia que las estrategias metodológicas utilizadas por las docentes para analizar los textos literarios les sirven y por eso las han adoptado aunque no se promuevan situaciones donde la literatura se vea arropada por su verdadera función social y cultural. Como resultado no se impulsa la participación activa de los estudiantes en actos de intercambio que tengan propósitos explícitos, pero sí se practican planteamientos que otorgan a la literatura una naturaleza restrictiva y no representativa, privada de su relación con el contexto, porque éste aparece como mero fondo en el que los hechos literarios ocurren sin vínculos. 
- La enseñanza que reciben los estudiantes para analizar los textos literarios no sólo se centra en los elementos formales del texto sino que se guía la lectura a un enfoque moralizante de la literatura. Los alumnos leen como les indica la profesora, no es posible otra lectura en donde la libre expresión y las actitudes creativas y críticas sean protagonistas en este proceso.

De este modo, el texto literario se convierte para los estudiantes en un campo al que accesan con el propósito de encontrar una enseñanza.

- Las profesoras son poseedoras del conocimiento y los estudiantes solamente reciben ese conocimiento, lo acumulan y ejercitan para la evaluación. En este sentido, los alumnos no participan, no son incluidos dentro de un proceso de enseñanza-aprendizaje que los retroalimente, su papel es optar por la conducta de silencio: la docente habla, los estudiantes escuchan, la profesora sabe y los estudiantes no.

Aunque los objetivos que plantea el MEP están orientados a desarrollar un aprendizaje significativo, los alumnos no reciben la información de modo sustancial, su incorporación dentro de la estructura cognoscitiva es arbitraria y la información se establece sin tomar en cuenta el conocimiento previo.

Se evidencia un enfoque conductista de enseñanza en donde no se visualizan estrategias metodológicas para acercar a los estudiantes a los textos literarios, asimismo, una actitud apática por parte de los alumnos que responde a una dinámica unidireccional en donde los estudiantes no logran ser protagonistas de su aprendizaje, ya que éstos saben mecánicamente qué deben hacer en cada inicio de la lectura de un texto: saben que algún compañero leerá el argumento, luego resolverán la práctica del libro de texto y, finalmente, también resolverán la guía del cuaderno.

Ante estas conclusiones cabe destacar que son varios los elementos que inciden en la problemática de cómo se enseña literatura en estos tiempos. Sin embargo, solamente a partir del conocimiento de la realidad de las aulas a través de diagnósticos regulares y estructurados de un grupo de especialistas, podrán derivarse planes y estrategias, opciones metodológicas y formas de actuar que ayuden a transformar la realidad en el sentido deseado.

El docente debe operar en el diseño de su tarea no como un transmisor sino como quien estudia, selecciona y organiza, en perspectiva histórica, el material literario en función de sus alumnos. Necesita diseñar estrategias para comentar textos literarios en clase con una pauta de análisis que profundice en las formas literarias porque, sólo de esta manera, se puede comprender el texto y, por tanto, apreciar la literatura.

Unido a lo anterior, es indispensable favorecer en las aulas la experiencia de la comunicación literaria ya que los alumnos avanzarán en su competencia literaria en la medida en que entiendan que los textos literarios están presentes en la vida cotidiana de nuestras sociedades. Es decir, que entiendan la literatura no sólo como una experiencia estética de carácter personal sino también como un tipo específico de comunicación que tiene lugar en determinados contextos.

Para que esta tarea sea exitosa, es necesaria la creación de una cultura de colaboración y capacitación en la que se ofrezcan a los profesores nuevas iniciativas, nuevos papeles y mayor autonomía. Las capacitaciones deben impartirse atendiendo sus verdaderas necesidades e inquietudes. El discurso de estas debe ser accesible y sobre todo aplicable a la realidad de aula. En este sentido se debe priorizar la capacitación a grupos de docentes como una tarea continua y actualizada. 
En pleno siglo XXI es necesario llevar a la acción una escuela renovada que trascienda la instrucción formal y transmisiva, se necesitan docentes que atiendan a la dinámica real de lo que nos circunda, para fomentar el desarrollo autónomo y la creatividad de la colectividad. De este modo, construir un ambiente integrador y significativo que aumente la comprensión de lo que está ocurriendo en una sociedad en donde se requiere de profesores con vocación y sobre todo con una formación acorde con el mundo, las ideas e inquietudes de los adolescentes.

\section{Bibliografía}

Amoretti H., María. 1992. Diccionario de términos Asociados en Teoría literaria. San José: Editorial Universidad de Costa Rica.

Ausubel, Novak Hanesian. 1983. Psicología educativa: Un punto de vista cognoscitivo. México: Editorial Trillas.

Carrete Lázaro, Fernando. 1974. Diccionario de términos filológicos. Madrid: Editorial Gredos.

Carvajal, Francisco y Joaquín Ramos. 2003. "Leer, comprender e interpretar en un aula que investiga". Textos de didáctica de la lengua y de la literatura. 33 (1): 11- 23.

Díaz Mandragón, Leda. 1997. Identidad y sociedad informatizada. San José: Editorial Universidad de Costa Rica.

Lomas, Carlos. 2003. "Leer y entender". Textos de didáctica de la lengua y de la literatura. 33 (1): $7-10$.

López Casanova, Martina. 2005. Enseñar literatura: fundamentos teóricos. Propuesta didáctica. Buenos Aires: Editorial Manantial.

Madalena, José Ignacio. 2003. "Hacer cosas con la lectura”. Textos de didáctica de la lengua $y$ de la literatura. 33 (1): 34- 42.

Martín- Barbero, Jesús. 2002. “Jóvenes: comunicación e identidad”. Revista de Cultura. Universidad Nacional Autónoma de México. Organización de Estados Iberoamericanos. www.oei.es/pensariberoamerica/temas.htm\#edu.

Méndez, Silvia. 2000. "La mediación docente en la comprensión de lectura de textos literarios". Revista Educación 24 (1): 89- 105.

Morales Cordero, Elsa María. 2002. Leer y pensar 7: antología literaria. San José: Editorial Santillana. 
Núñez, María Pilar. 2003. "La formación del profesorado de lengua y literatura: el difícil camino de la innovación”. Textos de didáctica de la lengua y de la literatura. 33 (1): 79- 103.

Ostria González, Mauricio. 2003. La enseñanza de la literatura en los tiempos que corren. Universidad de Concepción. www2.cyberhumanitatis.uchile.cl/14/tx26mostria.html.

Ovares, Flora y S Mora. 1986. La palabra al margen: la enseñanza del español en crisis. San José: Editorial Nueva Década.

Quiróz, María Teresa. 2003. Aprendizaje y comunicación en el siglo XXI. Bogotá: Editorial Norma.

Ramírez Molina, Catalina. 2007. Estrategias metodológicas utilizadas por las docentes de sétimo año en la enseñanza del análisis de textos literarios en el Liceo de Heredia. Tesis de Licenciatura. Universidad de Costa Rica.

Rojas Porras, Marta et al. 1998. Español 7: guía didáctica. San José: Editorial Universidad de Costa Rica: PROMECE, Ministerio de Educación Pública.

Sánchez Lozano, Carlos. 2003. ¿Porqué los jóvenes leen mal? Bogotá: Universidad Sergio Arboleda. http//matosas.typepad.com/libros/2005/05/porqu_losjvene.html.

Solano, María Rosa. 2000. “El proceso de enseñanza-aprendizaje de la lectura”. Revista Educación. 24 (2): 151- 156. 